 \\ Association between drug discrepancies and length of stay in the surgical clinic at a university hospital
}

\author{
Karine Barbosa de MENEZES ${ }^{1}$, Abiane de Souza SILVA ${ }^{1}$, Camila Elaine CUNHA-MATTOS ${ }^{1}$, Tammyrys NUTELS ${ }^{1}$, Alfredo Dias de OLIVEIRA ${ }^{2}$, \\ Sabrina Joany NEVES'2, Maria das Graças LEOPARDI-GONÇALVES ${ }^{1,2,3}$ (D)
}

${ }^{1}$ Programa de Residência em Saúde do Adulto e do Idoso da Universidade Federal de Alagoas; ${ }^{2}$ Grupo de Pesquisa em Assistência e Atenção Farmacêutica do Instituto de Ciências Farmacêuticas (ICF) da Universidade Federal de Alagoas (UFAL); ${ }^{3}$ Laboratório e Ensino e Pesquisa em Farmácia Clínica (LabFarClin) Hospital Universitário Professor Alberto Antunes (HUPAA) e Instituto de Ciências Farmacêuticas (ICF) da Universidade Federal de Alagoas (UFAL)

Corresponding author: Leopardi-Gonçalves MG, leopardi@icf.ufal.br

Submitted: 08-12-20 Resubmitted: 12-05-21 Accepted: 12-05-21

Peer review: blind reviewers

\begin{abstract}
Objective: This research aimed to verify the association between medication discrepancies at hospital admission and length of stay in surgical patients at a teaching hospital. Method: This is a retrospective cohort study, carried out with all inpatients in the surgical clinic between 2014 and 2018. Discrepancies were assessed by comparing the drugs of the first medical prescription in a hospital environment and the drugs listed in the best possible history of medication, a document that details the use of medications at home in the week before hospitalization. This information is obtained through a structured interview with the patient, applied by a clinical pharmacist in the first 24 hours of the patient's hospitalization. These patients were evaluated in two groups: (a) exposed to drug discrepancies and (b) not exposed. The data sources were the patient's pharmacotherapeutic and electronic medical records. The level of statistical significance was set at $p<0.005$. Results: 338 individuals were included, of these 187 (55.3\%) exposed to discrepancies. The average length of stay for the exposed was 11 days (SD = 23), whereas the unexposed group was 10.5 days $(S D=38) p=0.352$. In the group exposed to discrepancy, $112(80.6 \%)$ individuals had at least one comorbidity. The average length of stay of adults (age up to 59 years) exposed to drug discrepancies was 10.6 days (SD = 19.6) while that of those not exposed was 8.6 days $(S D=40.5) p=0.483$. In the group exposed to the discrepancy, $58(52.7 \%)$ adults had at least one comorbidity, $p=0.000$. The average length of stay of the elderly (age over 60 years) exposed to the medication discrepancy was 11.5 days $(S D=27)$ while for the elderly who were not exposed was 15.5 days $(S D=31.7) p=0.394$. In the group of elderly people exposed to discrepancy, $54(70.2 \%)$ individuals had at least one comorbidity. $p=0.000$. Conclusion: This result indicates that there is no association between drug discrepancies at hospital admission and length of stay. The occurrence of drug discrepancies is associated with patients with comorbidities and the elderly.
\end{abstract}

Keywords: medication discrepancies; length of stay; medication reconciliation; medication use; surgical clinic; medication errors.

\section{Associação entre discrepâncias medicamentosas e o tempo de internação na clínica cirúrgica em um hospital universitário}

\section{Resumo}

Objetivo: Verificar a associação entre a ocorrência de discrepâncias medicamentosas na admissão hospitalar e o tempo de internação em pacientes cirúrgicos em um hospital de ensino. Método: Trata-se de estudo de coorte retrospectivo, realizado com todos os pacientes internos na clínica cirúrgica no período compreendido entre os anos de 2014 a 2018. As discrepâncias foram avaliadas comparando os medicamentos da primeira prescrição médica em ambiente hospitalar e os medicamentos constantes na melhor história possível da medicação, documento este constituinte do prontuário farmacêutico que detalha o uso dos medicamentos em domicílio na semana que antecede a internação. Essas informações foram obtidas através de entrevista estruturada com o paciente, aplicada por farmacêutico clínico nas primeiras $24 \mathrm{~h}$ de entrada do paciente no hospital. Estes pacientes foram avaliados em dois grupos: (a) expostos a discrepâncias medicamentosas e (b) não expostos. As fontes de dados foram os prontuários farmacoterapêutico e eletrônico do paciente. O nível de significancia estatística foi estabelecido em p<0,005. Resultados: Foram incluidos 338 indivíduos, destes 187 (55,3 \%) expostos a discrepâncias medicamentosas. A média do tempo de internação dos expostos foi de 11 dias ( $D P=23$ ), já o grupo não exposto foi de 10,5 dias ( $D P=38) p=0,352$. Observou-se que o grupo de expostos a discrepância, $112(80,6 \%)$ indivíduos apresentavam pelo menos uma comorbidade. A média de tempo de internação dos adultos (idade até 59 anos) expostos a discrepâncias medicamentosas foi de 10,6 dias ( $D P=19,6)$ enquanto a dos não expostos foi de 8,6 dias $(D P=40,5)$ $p=0,483$. No grupo de expostos a discrepância, 58 (52,7\%) indivíduos adultos apresentaram pelo menos uma comorbidade, $p=0,000$. A média do tempo de internação dos idosos (idade acima de 60 anos) expostos à discrepância medicamentosa foi de 11,5 dias (DP=27). Em contrapartida, a média do tempo de internação dos idosos não expostos à discrepância foi de 15,5 dias ( $D P=31,7) p=0,394$. No grupo de idosos expostos a discrepância, 54 (70,2\%) indivíduos apresentavam pelo menos uma comorbidade. $p=0,000$. Conclusão: Este resultado sugere que não há associação entre discrepâncias medicamentosas na admissão hospitalar e o tempo de internação. A ocorrência de discrepâncias medicamentosas esteve associada a pacientes com comorbidades e idosos.

Palavras-chave: discrepâncias medicamentosas; tempo de internação; reconciliação medicamentosa, uso de medicamentos; clínica cirúrgica; erros de medicação. 


\section{Introduction}

Clinical pharmacy is the pharmacy area aimed at the rational use of medications, in which the pharmacists provide care to the patients, with the purpose of optimizing pharmacotherapy, promoting health and well-being. The clinical pharmacist acts in health promotion, prevention and monitoring of adverse events, in addition to intervening in the prescription of medications in order to obtain positive clinical results, improving the patients' quality of life and minimizing the therapy-related costs. ${ }^{1}$

Routinely, the review of the medications used by the patients is part of the clinical pharmacist's duty. Medication review is an intervention that is commonly performed by the clinical pharmacists aimed at improving drug safety and the health results, as well as at ensuring optimal use of the medications by the patients. Drug reconciliation includes obtaining the Best Possible Medication History (BPMH), as well as assessing the medication regarding suitability and possible/concrete occurrence of drug-related adverse events. ${ }^{2}$ Obtaining the BPMH consists of a systematic interview with the patient and/or companion, in addition to verifying another reliable information source, in order to obtain all the medications (prescribed and non-prescribed) in use at the time of hospital pre-admission. ${ }^{3}$

For governments, organizations and health institutions alike, preventing drug-related adverse events or complications caused by medications is a priority for patient safety. ${ }^{4}$ In this context, medication errors are considered as the main reasons for harms in hospitalized patients, and these situations can be avoided in the phases of the medication process. In order to prevent medication errors, and thus ensure patient safety, the organizations implemented, as an effective strategy, drug reconciliation at the transition points of care, admission, transfer and hospital discharge. ${ }^{4,5}$

Faced with different definitions of drug reconciliation used by various organizations, such as The Joint Commission (TJC), ${ }^{6}$ the Institute of Healthcare Improvement $(\mathrm{IHI})^{4}$ and the World Health Organization (WHO), ${ }^{7}$ Pan American Health Organization/World Health Organization, ${ }^{8}$ for this study, we consider the definition proposed by the $\mathrm{IHI}$ : "the process of creating the most accurate list possible of all the medications that a patient is taking including the name of the medication, dosage, frequency and route - and comparing it with the prescriptions for admission, transfer and/or medical discharge with the purpose of providing correct medications to the patient at all transition points within the hospital". ${ }^{4}$

Drug reconciliation is a care quality assurance process, leading to the detection of medication errors, in this context called drug discrepancies (DDs), defined as any difference between the patients' pre-hospital medication history and their prescription at the time of hospital admission, in the patients' care transition at the hospital and at hospital discharge. DDs include the following: omission or introduction of a medication upon admission, replacement of the medication by another drug of the same pharmacotherapeutic class and changes in dose, frequency or administration route, among others. ${ }^{9}$

In their daily work, clinical pharmacists can support the patient safety actions with regard to medication reconciliation, as we will now describe. It is part of their daily activity with the patients both to obtain the complete history of the medication in their home environment, in the week before hospitalization [and generate the first list of medications to be compared] such as the validation of the first medical prescription in the hospital environment [generating the second list]. Comparing the two lists, the DDs are obtained at hospital admission and from there, medication reconciliation can be performed. Thus, considering the scarcity of data in the literature, this research aimed at verifying the association between DDs at hospital admission and length of stay in surgical patients in a teaching hospital.

\section{Methods}

\section{Design and data source}

This is a retrospective cohort study. The study participants were all the patients hospitalized in the surgical clinic of the Prof. Alberto Antunes University Hospital of the Federal University of Alagoas - HUPAA/UFAL, who were interviewed by a clinical pharmacist in the 2014-2018 period. The HUPAA is a high- and mediumcomplexity hospital, with 209 beds, with 170 hospitalization beds in the clinics (four wards with six beds each in the surgical clinic) and 10 ICU beds. It has seven operating rooms and six anesthetic recovery beds. It offers the following specialties in surgery: Head and Neck Surgery, Digestive Tract Surgery, General Surgery and Plastic Surgery. The surgical clinic has four wards with six beds each. The data sources were the patients' pharmacotherapy and electronic charts. The inclusion criteria were all the patients admitted to the surgical clinic during the period studied, whose BPMHs were on their pharmaceutical records and were obtained within an interval of up to 24 hours after admission. The exclusion criteria were patients under the age of 18 and patients who had incomplete BPMHs. This study was approved by the CEP of the UFAL, under number 3,202,187.

\section{First stage}

An instrument was developed to collect data from the pharmaceutical and medical records of the individuals included in the study, which contemplated information on sociodemographic characteristics, such as age and gender; in addition to information related to the variables under study, such as: place of hospitalization; reason for hospitalization; comorbidities; length of stay in the hospital; pre-admission medications (obtained from the pharmacotherapeutic record); medications prescribed at admission (electronic patient record); DDs ${ }^{9}$ (defined as the presence of variation in the therapeutic strategy at care transition, in this study, considering the transition from outpatient treatment and admission to the hospital environment); number of DDs identified and the type of DD (classified as omission, administration route, dosage and dose).

The pharmaceutical record is the instrument for recording all the work done by the resident clinical pharmacist and, in addition to the BPMH, the plans of pharmaceutical care for the daily monitoring of the patient and the identification of problems related to medications are also recorded in it, among others. It is part of the daily activity of the resident clinical pharmacist to review the patients' pharmacotherapy, which includes, among others, obtaining the patients' complete medication history in their home environment, in the week before their hospitalization, called BPMH. Subsequently, a structured interview is conducted with the patients, encompassing all the aspects related to medication use. 


\section{Second stage}

In order to identify the existing DDs (exposure), the medications used by the patient at pre-admission (listed in the NPMH), and those of the first therapy prescribed at the time of hospital admission were compared and checked by four clinical pharmacists. Two cohorts of patients were assembled: those who presented DDs and those who did not. The mean hospitalization time in days was calculated for each group.

The main variables studied were 1) Drug Discrepancies, dichotomous variable: Exposed to Discrepancy at Hospitalization/ Not exposed to Discrepancy at Hospitalization. For knowledge of this variable, it was detailed in its various dimensions: a) Elaboration and comparative analysis of two lists of medications. List 1, consisting in all the medications that the patients used in their home environment and the way in which they administered them, and List 2, consisting in the medications that the patients received in the first prescription in the hospital environment. The presence of a discrepancy was confirmed when, after analyzing the two lists, the medications in List 2 differed from those in List 1 , as regards those used for the treatment of chronic diseases. Overthe-counter medications, indicated for symptomatic treatments, were excluded 2) Comorbidities: dichotomous variables. Presented comorbidities/Did not present comorbidities. Definition: it refers to the previously diagnosed chronic diseases. 3) Hospitalization time: numerical variable. It is defined as the period of time between admission in the clinic and hospital discharge or transfer to another hospital sector, measured in days.

The sample under study was stratified in two age groups: less than 60 years old and 60 years old or more.

\section{Data analysis}

The variables were expressed as measures of central tendency and dispersion (mean \pm standard deviation) and the qualitative variables, as frequencies. For the bivariate analysis, the chi-square distribution and the $T$ test for independent samples were used. The statistical significance level was set at $p<0.05$. The statistical analysis was performed in the Statistical Package for Social Sciences (SPSS) statistical program.

\section{Results}

\section{Characterization of the sample}

A total of 338 individuals were analyzed, of which 187 (55.3\%) were exposed to drug discrepancies (DDs). Regarding the characteristics of the groups evaluated, it was observed that, in both groups, female patients were more prevalent, although the group of individuals exposed to DDs presented higher prevalence of older adults and patients with comorbidities, presenting prevalence values $14.9 \%$ $(p=0.007)$ and $32.1 \%(p=0.000)$ higher, respectively.

The most frequent type of DD was related to medication omission. Among the 187 individuals who presented DDs, 93\% (174) presented the type of discrepancy due to medication omission. The other types of discrepancy occurred in 7\% [13] of the total number of individuals with DDs. Regarding the occurrence of DDs and the presence of comorbidity, it was observed that, in the group exposed to discrepancies, $112(80.6 \%)$ individuals presented at least one comorbidity, with $\mathrm{p}=0.000$ (Table 1 ).
Table 1. Drug discrepancies related to gender, age and comorbidity in patients admitted to the surgical clinic of a teaching hospital. Alagoas, Brazil, 2014-2018.

\begin{tabular}{llll}
\hline Drug discrepancy & & & \\
\hline Gender & Yes & No & p \\
Male & & & \\
$\begin{array}{l}\text { Female } \\
\text { Age }\end{array}$ & $77(41.2 \%)$ & $67(44.4 \%)$ & 0.555 \\
$\begin{array}{l}<60 \text { years old) } \\
\text { ( } \geq 60 \text { years old) }\end{array}$ & $110(58.9 \%)$ & $84(55.6 \%)$ & \\
Comorbidity & $77(41.2 \%)$ & $41(27.2 \%)$ & \\
Yes & & & \\
No & $112(59.8 \%)$ & $27(17.0 \%)$ & 0.000 \\
\hline
\end{tabular}

\section{Hospitalization time in the surgical clinic}

In the surgical clinic, the mean length of stay of the group exposed to discrepancies (187 individuals) was 11 days ( $S D=23)$; on the other hand, in the unexposed group (151 individuals) it was 10.5 days $(\mathrm{SD}=38$ ), with $\mathrm{p}=0.352$ (Table 2 )

Table 2. Drug discrepancies related to length of stay in days in patients admitted to the surgical clinic of a teaching hospital. Alagoas, Brazil, 2014-2018.

\begin{tabular}{lll}
\hline DD & Hospitalization time in days & $\mathbf{p}$ \\
\hline Entire sample & $11 \pm 23^{*}$ & 0.352 \\
Yes & $10.5 \pm 38^{*}$ & \\
No & & \\
Adults aged $<\mathbf{6 0}$ years old & $10.6 \pm 19.6^{*}$ & 0.483 \\
Yes & $8.6 \pm 40.5^{*}$ & \\
No & & \\
Adults aged $\mathbf{6 0}$ years old & $11.5 \pm 27^{*}$ & 0.394 \\
Yes & $15.5 \pm 31.7^{*}$ & \\
No &
\end{tabular}

\section{Patients aged less than 60 years old}

The mean length of hospital stay for patients aged from 19 to 59 years old, exposed to DDs, was 10.6 days ( $S D=19.6)$. The mean length of stay of adults not exposed to DDs was 8.6 days ( $S D=40.5)$, with $p=0.483$ (Table 2). Regarding the occurrence of DDs and the presence of comorbidity in these patients, it was observed that, in the group of people exposed to discrepancies, 58 (52.7\%) individuals presented some comorbidity, with $p=0.000$ (Table 3).

\section{Aged patients}

The mean length of stay of the older adults (aged 60 years old or more) exposed to the drug discrepancies was 11.5 days (SD=27). On the other hand, the mean length of stay for the older adults who were not exposed to discrepancies was 15.5 days $(S D=31.7)$, with $p=0.394$ (Table 2). Regarding the occurrence of DDs and the presence of comorbidity, it was observed that, in the group exposed to discrepancies, 54 (70.2\%) aged individuals presented some comorbidity, with $\mathrm{p}=0.000$ (Table 3 ). 
Table 3. Age-related comorbidities associated with discrepancies in patients admitted to the surgical clinic of a teaching hospital. Alagoas, Brazil, 2014-2018.

\begin{tabular}{llll}
\hline Comorbidity & \multicolumn{2}{l}{ Drug Discrepancy } & p \\
\hline Adults aged $<60$ & Yes & No & \\
Yes & & & \\
No & $58(52.7 \%)$ & $16(14.5 \%)$ & 0.000 \\
Adults aged $\geq 60$ & $52(47.2 \%)$ & $94(85.4 \%)$ & \\
Yes & & & \\
No & $54(70.2 \%)$ & $11(26.8 \%)$ & 0.000 \\
\hline
\end{tabular}

\section{Discussion}

The main findings of this research pointed out that the difference found in hospitalization times between the two cohorts comprised of patients exposed and not exposed to DDs at hospital admission was not statistically significant, as shown in Table 2. Regarding the age of the patients under study, 118 (34.9\%) were aged adults, over 60 years old, of whom 77 (65.3\%) were exposed to DDs at admission. The number of aged individuals exposed to DDs was $15 \%$ higher than that of non-elderly people exposed, with $p=0.007$ (Table 1). These results suggest that old age can be a risk factor for exposure to DDs at hospital admission.

When assessing the incidence of drug discrepancies and their related factors in patients admitted to the emergency department of hospitals at the University of Medical Sciences in Tehran, the authors of an Iranian study ${ }^{10}$ also found an association between the number of comorbidities and the presence of drug discrepancies, with statistically significant results, which corroborates with the results of this study. On the other hand, in order to better assess the impact of the discrepancies, it is recommended to conduct new and more specific studies with patients with comorbidities or similar diseases, aiming at eliminating possible confounding factors such as age. Aged individuals usually use more medications and suffer from chronic diseases, which in itself increases the possibility of exposure to discrepancies.

The most frequent type of DD found was related to medication omission. Among the individuals who presented DDs, 93\% (174) were classified as medication omission. These data are corroborated by the results found in a study conducted in Toronto (Canada)9, which also reported that the most common type of drug discrepancy in both adults and aged individuals at hospital admission was omission of medication that the patient was taking before admission.

In this study, the BPMH report, which is part of the patient's pharmaceutical record, was used as a data source, so that a stage of the pharmacist's clinical work supported an activity of care quality assurance, namely: patient safety regarding medication use.

Another Canadian study ${ }^{2}$ evaluated whether the review of medications performed by clinical pharmacists in the emergency department at three hospitals could reduce the length of hospital stay among high-risk patients who were hospitalized compared to usual care. The authors found that the mean number of days spent in hospital was reduced by 0.48 days in the medication review group compared to the control group (without medication review), representing a relative reduction of $8 \%$ in the number of days spent at the hospital during the follow-up period. This difference was more pronounced among the patients under the age of 80 , who spent a mean of 0.60 fewer days in the hospital, representing a relative reduction of $11 \%$ in the number of days spent in the hospital during follow-up. As well as ours, this study showed the importance of the reconciliation procedure and of the processes involved in hospital admission in charge of clinical pharmacists.

The same Canadian study ${ }^{9}$ cited above, prospectively identifying unintentional discrepancies (medication errors) between the admission medication orders by the physicians and a comprehensive history of medication use obtained by a pharmacist and assessing the potential clinical significance of these discrepancies in a tertiary-level teaching hospital affiliated with the University of Toronto, found that $53.6 \%$ of the patients studied presented at least one unintentional discrepancy at admission. The overall rate of unintentional discrepancies was 0.93 per patient. The same study also indicated that most of the patients presented drug discrepancies. Thus, they indicate that discrepancies are common at hospital admission, corroborating the results presented in this study.

In our study, drug discrepancies were not classified as intentional or unintentional, given the uncertainty of these terms and the difficulty in attributing intention to the actions of other people (medication prescribers). The use of these terms is open to interpretation, since it is difficult (or impossible) for an independent person to determine, in a retrospective study, whether another person's actions were intentional or not. 5,10,11

Another aspect to consider is that, although all the information concerning the types of surgical procedures, medications related to the discrepancies, and the types of chronic diseases that the patients had was collected, these data did not undergo any statistical treatment for each of them were presented in a wide variety of types.

It is noteworthy that few studies evaluated the potential clinical importance of drug discrepancies and there are no data in the literature regarding the influence of drug discrepancies on hospital stay, therefore, this is the first study with such an approach.

Our results on the number of discrepancies can be overvalued since, in this study, we only considered the medications of the first written medical prescription, which is in the patient's medical record and since, due to the retrospective characteristic of the research, we do not take into account if there was an oral prescription by the physicians to the patients, guiding them to continue taking the medications brought from their homes.

\section{Conclusion}

The results of this study suggested that there is no association between drug discrepancies at hospital admission and the length of hospital stay for surgical patients. The assessment of the discrepancies seems to be more relevant for patients with comorbidities and aged, who are at a higher risk of discrepancies. It is important to include the analysis of discrepancies as a priority in the care protocol for patients with comorbidities and aged. Future studies can include patients with similar comorbidities, patients with similar types of surgeries, or patients who use specific groups of medications. 


\section{Funding sources:}

The authors, KBM, ASS, TN and CEM, received a scholarship from the Ministry of Education, from the MEC's Health Multiprofessional Residency Program.

\section{Collaborators}

KBM and ASS: Writing of the article, design, data analysis and interpretation. TN and CEM: Design, data analysis and interpretation. ADO and SJN: Conception, relevant critical review of the intellectual content, data analysis and interpretation. MGL: Conception and design. Data analysis and interpretation. Writing of the article and relevant critical review of the intellectual content. Conduction of the research.

\section{Conflict interest statement}

The authors declare that there are no conflicts of interest regarding this article

\section{References}

1. American College of Clinical Pharmacy (ACCP). The Definition of Clinical Pharmacy. Pharmacotherapy. 2008; v. 6, n. 28, p.816-817. Available in: https://www.accp.com/docs/positions/commentaries/Clinpharmdefnfinal.pdf Access in: 20 July 2019.

2. Hohl CM, Partovi N, Ghement I, et al. Impact of early in-hospital medication review by clinical pharmacists on health services utilization. PLoSONE. 2017; 12(2): e0170495.

3. The Institute for Safe Medication Practices Canada. (ISMP) Medication reconciliation in Acute Care (MedRec), 2011 [online]. Available in: https://www.ismp-canada.org/download/MedRec/Medrec_AC_English_GSK_V3.pdf Access in: 20 July 2019.

4. Institute for Healthcare Improvement. Medication reconciliation to prevent adverse drug events [online]. Available in: http://www.ihi.org/topics/adesmedicationreconciliation/ Pages/default.aspx Access in: 20 July 2019.

5. Vasileff HM, Whitten LE, Pink J A, et al. The effect on medication errors of pharmacists charting medication in an emergency department. Pharm World Sci. 2009; Jun;31(3):373-9. Available in:. Access in: 20 July 2019.

6. The Joint Commission on Accreditation of Healthcare Organizations. Using medication reconciliation to prevent errors Jt Comm J Qual Patient Saf. 2006 Apr;32(4):230-2. DOI: 10.1016/s1553-7250(06)32030-2 Available in: http://www. jcaho.org/SentinelEvents/SentinelEventAlert/sea_35.htm Access in: 20 May 2019.

7. World Health Organization. Action on patient safety - the high 5s project, 2013 [online]. Available at https://www.who. int/patientsafety/implementation/solutions/high5s/High5_ InterimReport.pdf Access in: 20 July 2019.

8. Organização panamericana de Saúde/ Organização Mundial de Saúde OPAS/OMS no Brasil. Capucho, HC
Monitoramento e Avaliação Farmacoterapêutica: o medicamento fez efeito? Qual? In Uso racional de Medicamentos: fundamentação em condutas terapêuticas e nos macroprocessos da Assistência Farmacêutica. Vol 1 ,No.20 Brasília, 2016. Available in: https://www.paho. org/bra/index.php?option=com_docman\&view=download\&category slug=serie-uso-racional-medicamentos-284\&alias $=1548$-monitoramento-e-avaliacao-farmacoterapeutica-o-medicamento-fez-efeito-qual-8\&Itemid=965 Acessado em 20 July 2019.

9. Cornish, PL, Knowles SR, Marchesano R, et al. Unintended medication discrepancies at the time of hospital admission. Archives of internal medicine. 2005; 165(4): 424-9. https:// pubmed.ncbi.nlm.nih.gov/15738372 (March 12, 2012). Access in: 20 July 2019.

10. Zarif-Yeganeh M, Rastegarpanah M, Garmaroudi G, et al. Incidence of Medication Discrepancies and Its Predicting Factors in Emergency Department. IRAN J PUBLIC HEALTH 2017; 46,(8): 1086-94 Available in: https://www.ncbi.nlm.nih.gov/ pmc/articles/PMC5575388/. Access in: 20 July 2019.

11. Almanasreh E, Moles R, Chen TF. The medication reconciliation process and classification of discrepancies: a systematic review. Br J Clin Pharmacol. 2016;82:645-58. 